(c) American Dairy Science Association, 2006.

\title{
Modeling of Lactose Crystallization and Color Changes in Model Infant Foods
}

\author{
A. Nasirpour, ${ }^{*}$ J. Scher, M. Linder, and S. Desobry \\ Laboratoire de Science et Génie Alimentaires, Ecole Nationale Supérieure d'Agronomie et des Industries Alimentaires, \\ INPL, Vandoeuvre-lès-Nancy cedex, France
}

\begin{abstract}
Lactose crystallization and color changes in formulas containing $\beta$-lactoglobulin and gelatinized starch were investigated. Model infant formulas were prepared by colyophilization of 3 components (lactose, $\beta$ lactoglobulin, and gelatinized starch). A mixture design was used to choose the percentage of each mixture component. These formulas were stored for $3 \mathrm{mo}$ at different relative humidities $(\mathrm{RH})$, ranging from approximately 0 to $94.6 \%$, to study the lactose crystallization and color changes. Crystallization kinetics was studied by gravimetric methods, and lactose state (crystalline vs. amorphous) was verified before and after storage by differential scanning calorimetry. Before storage, lyophilized lactose was amorphous, but during storage it crystallized, depending on the $\mathrm{RH}$. The lactose crystallization RH depended on the quantity of $\beta$-lactoglobulin and gelatinized starch, and by increasing these quantities, the crystallization $\mathrm{RH}$ increased. For some formulas, the crystallization $\mathrm{RH}$ was noted at 3 different $\mathrm{RH}$ during storage. The first was noted after $1 \mathrm{~d}$ of storage and the second and third were observed later on, showing that crystallization is a time-dependent phenomenon. Nonenzymatic browning was studied in model infant formulas by yellow color changes of samples at 11.3, 43.2, 54.5, and $75.4 \% \mathrm{RH}$. In this study, 7 mathematical models were proposed to predict the moisture sorption properties and color changes at different $\mathrm{RH}$, and the models were validated by experimental results.
\end{abstract}

Key words: lactose crystallization, moisture sorption isotherm, color change

\section{INTRODUCTION}

The handling and storage of powders containing lactose are very difficult because of crystallization and interactions between lactose and other formula components such as proteins. Crystallization causes the most

Received December 5, 2005.

Accepted February 5, 2006.

*Corresponding author: ali.nasirpour@ensaia.inpl-nancy.fr dramatic changes in the physical properties of food polymers (Roos and Karel, 1992; Roos, 1995). Lactose crystallization in milk powders leads to flavor deterioration and an increased amount of free fat, and may promote nonenzymatic browning (Kim et al., 1981). Crystallization could be delayed by incorporating high molecular weight substances (Levine and Slade, 1986) or other sugars (Herrington and Brandfield, 1984). Numerous authors (Jouppila et al., 1997; Buckton and Darcy, 1999; Nasirpour et al., accepted) have studied lactose crystallization, which is known to be affected by many factors, such as temperature, relative humidity (RH; Vuataz, 2002), storage time, and the composition of the mixture (e.g., proteins in milk powder or infant foods). The rate of crystallization increases as the $\mathrm{RH}$ increases during storage. As many researchers have shown, lactose crystallization occurs above the glass transition temperature $\left(\boldsymbol{T}_{\mathbf{g}} ;\right.$ Roos, 1995). If the storage temperature is higher than the $T_{\mathrm{g}}$, crystallization occurs as molecular mobility and diffusion increase and as viscosity decreases exponentially above $T_{\mathrm{g}}$ (Slade and Levine, 1991). Knudsen et al. (2002) studied the induction and kinetics of lactose crystallization in infant formula and whole milk. They showed that the induction time for infant formula and milk powder is longer than for pure lactose. Infant formula and milk powder contain protein, and crystallization of lactose is delayed due to a competitive absorption of water (Knudsen et al., 2002).

A model infant formula was chosen for economic and technological reasons because of the high content of lactose and interactions between proteins, lactose, and starch. As in numerous literature studies, $\beta$-LG was chosen as a model protein because of its functional properties. Moreover, whey proteins are added to most infant formulas (Jost et al., 1999). In this study, the crystallization of lactose, the effect of $\beta$-LG and starch on lactose crystallization, and the interactions among these 3 components were studied using an experimental design.

\section{MATERIALS AND METHODS}

\section{Model Infant Formula Preparations}

Model formulas were prepared by mixing 3 major components of infant formulas (lactose, $\beta$-LG, and 
Table 1. Initial experimental area for formulas

\begin{tabular}{lll}
\hline Component & $\begin{array}{l}\text { Minimum, } \\
\%(w t / w t)\end{array}$ & $\begin{array}{l}\text { Maximum, } \\
\%(w t / w t)\end{array}$ \\
\hline Lactose & 50 & 80 \\
Starch & 10 & 25 \\
$\beta$-LG & 10 & 25 \\
\hline
\end{tabular}

starch) according to the European standard for infant formula (Food Safety Authority of Ireland, 2001). A mixture design was used to cover the ratios of components in the ranges indicated in the standard (see Table 1). Starch is not required in the European standard for infant formula but is beneficial to study, as its nutritional and functional properties have led to its use in some formulas on the market. When starch is present in formulas, precooked or cooked starch must be used; thus, in this study gelatinized starch was used. Gelatinized wheat starch (Sigma Chemical Co., St. Louis, MO) was produced using 5\% (wt/wt) solids suspensions. The suspensions were heated to boiling under continuous stirring to obtain gelatinized starch. Full gelatinization was confirmed by polarized light microscopy. After cooling, this solution was mixed with a $\beta$-LG (Davisco Foods International, Inc., Eden Prairie, MN) solution (10\%) and a lactose (Prolabo, Fontenay-sous-Bois, France) solution (15\%) at different ratios to obtain the formulas presented in Table 2. After $30 \mathrm{~min}$ of mixing, $70 \mathrm{~mL}$ of the final mixture was placed into a $500-\mathrm{mL}$ round-bottomed flask and frozen at $-40^{\circ} \mathrm{C}$ for $45 \mathrm{~min}$ in a refrigerating bath (Polystat cc241; Peter Huber Kältemaschinenbau GmbH, Offenburg, Germany). The samples were then freeze-dried (Christ Alpha 1-2; Christ Gefriertrocknungsanlagen GmbH, Osterode am Harz, Germany) for $48 \mathrm{~h}$ at $-60^{\circ} \mathrm{C}$ and $10 \mathrm{~Pa}$. The water content of all samples was measured after freeze-drying, and all contained less than $2 \%$ water (dry basis). The samples were stored for $2 \mathrm{wk}$ on $\mathrm{P}_{2} \mathrm{O}_{5}$ to complete the drying process. Three samples of each formula were kept on $\mathrm{P}_{2} \mathrm{O}_{5}$ for 3 mo to determine the initial water content of the samples. The amorphous state of powders was checked by differential scanning calorimetry (DSC). In this study, the colyophilized formulas contained 3 components and will be referred to as F-lactose/starch/ $\beta$-LG (by wt). For example, F80/10/10 means the formula contained $80 \%$ lactose, $10 \%$ gelatinized starch, and $10 \% \beta$-LG (by wt).

\section{Moisture Sorption Isotherms}

The moisture sorption properties of the formulas were determined by gravimetric methods. A 0.5-g quantity of each sample was placed in a desiccator over a saturated salt solution at $20^{\circ} \mathrm{C}$. The salts used were $\mathrm{LiCl}, \mathrm{CH}_{3} \mathrm{COOK}, \mathrm{MgCl}_{2}, \mathrm{~K}_{2} \mathrm{CO}_{3}, \mathrm{Mg}\left(\mathrm{NO}_{3}\right)_{2}$, $\mathrm{NaBr}, \mathrm{KI}, \mathrm{NaCl}, \mathrm{KCl}$, and $\mathrm{KNO}_{3}$, with respective $\mathrm{RH}$ of 11.3, 23.1, 33.1, 43.2, 54.5, 58.7, 69, 75.4, 85.1, and 94.6\% (Greenspan, 1977). The weight changes of each sample were measured after 1,3 , and $7 \mathrm{~d}$ and each week for 3 mo to study the crystallization kinetics. Because crystallization could occur between $2 \mathrm{RH}$, in this paper the limit of crystallization $\mathrm{RH}$ was the minimum $\mathrm{RH}$ at which lactose crystallized.

\section{State of the Lactose}

Differential scanning calorimetry measurements were carried out with a PerkinElmer Pyris 1 (PerkinElmer, Norwalk, CT) for the formulas stored at $\mathrm{RH}$ ranging from approximately 0 to $85.1 \%$. The DSC instrument was calibrated using indium, with an empty pan used as the reference. The states of the lactose were determined by scanning samples (approximately $5 \mathrm{mg})$ in an open aluminum DSC pan $(50 \mu \mathrm{L})$ at temperatures ranging from 25 to $250^{\circ} \mathrm{C}$, heated at $10^{\circ} \mathrm{C} / \mathrm{min}$ under a nitrogen atmosphere.

\section{Color}

The color of samples was measured by Microflash 200d (Datacolor International, Montreuil, France). This equipment measures the chromatic space CIE L* $a^{*} b^{*}$. The parameter $L^{*}$ corresponds to luminance, and $a^{*}$ and $b^{*}$ are the green-red and blue-yellow scales, respectively. Figure 1 shows these indexes. Color changes were studied at $\mathrm{RH}$ of approximately $0,11.3$, 43.2 , and $75.4 \%$ during storage.

\section{Statistical Analysis}

A mixture design based on a 3-component mixture was used to explore the results in terms of moisture sorption and color changes. The experimental domain was chosen according to the European standard for infant formula (Food Safety Authority of Ireland, 2001) as shown in Table 1. Mixture design is an efficient method of studying the effect of several parameters to distinguish among process variables (i.e., temperature, $\mathrm{RH}, \mathrm{pH}$, etc.) and mixture factors such as components of the formula (Cafaggi et al., 2003). When working with 3 components, the experimental domain corresponded to a triangle. All the possible mixtures could be identified by a point in this space, with vertices corresponding to the pure components. The experimental results were analyzed using Expert-Design 6.0.6 trial (Stat-Ease Inc., Minneapolis, MN). An ANOVA was performed to determine the statistical sig- 
Table 2. Composition of infant formulas, minimum relative humidities $(\mathrm{RH})$ at which lactose crystallized, and moisture sorption (\% wt/wt, dry basis) at $94.6 \% \mathrm{RH}$

\begin{tabular}{|c|c|c|c|c|c|}
\hline \multirow[b]{2}{*}{ Formulation $^{1}$} & \multicolumn{3}{|c|}{ Composition, \% } & \multirow{2}{*}{$\begin{array}{l}\text { Crystallization } \\
\mathrm{RH}, \%^{2}\end{array}$} & \multirow{2}{*}{$\begin{array}{l}\text { Moisture } \\
\text { sorption, \% }\end{array}$} \\
\hline & Lactose & Starch & $\beta$-LG & & \\
\hline F80/10/10 & 80 & 10 & 10 & $58.7[1], 54.5[21]$ & 10.54 \\
\hline F65/10/25 & 65 & 10 & 25 & 69 [3], $58.7[7]$ & 16.06 \\
\hline F65/25/10 & 65 & 25 & 10 & $69[1], 58.7[14], 54.5[92]$ & 14.45 \\
\hline F50/25/25 & 50 & 25 & 25 & $75.4[1], 69[14]$ & 20.77 \\
\hline F72.5/10/17.5 & 72.5 & 10 & 17.5 & 69 [1], $58.7[3], 54.5$ [70] & 14.25 \\
\hline F72.5/17.5/10 & 72.5 & 17.5 & 10 & $69[1], 58.7[3], 54.5[70]$ & 12.42 \\
\hline F57.5/17.5/25 & 57.5 & 17.5 & 25 & 69 [3], 58.7 [28] & 18.51 \\
\hline F57.5/25/17.5 & 57.5 & 25 & 17.5 & $69[3], 58.7[21]$ & 17.60 \\
\hline $\mathrm{F} 65 / 17.5 / 17.5$ & 65 & 17.5 & 17.5 & 69 [1], $58.7[14]$ & 15.36 \\
\hline F72.5/13.75/13.75 & 72.5 & 13.75 & 13.75 & $69[1], 58.7[3], 54.5[56]$ & 12.62 \\
\hline F65/13.75/21.25 & 65 & 13.75 & 21.25 & 69 [1], 58.7 [21] & 16.28 \\
\hline F65/21.25/13.75 & 65 & 21.25 & 13.75 & 69 [1], $58.7[21], 54.5$ [49] & 16.06 \\
\hline F57.5/21.25/21.25 & 57.5 & 21.25 & & 69 [3], 58.7 [92] & 18.30 \\
\hline
\end{tabular}

${ }^{1}$ Lactose/starch/ $\beta$-LG (by wt).

${ }^{2}$ The values in brackets show the end of crystallization in days (i.e., sample weights were stable).

nificance of the fitted models. Finally, the models were validated with the new formulas.

\section{RESULTS AND DISCUSSION}

\section{Moisture Sorption Isotherms}

After 2 wk of powder storage on $\mathrm{P}_{2} \mathrm{O}_{5}$, moisture sorption isotherms were measured by storing the samples at different RH. Figure 2 shows the moisture sorption isotherms of lactose, starch, and $\beta$-LG and 2 model infant formulas at $20^{\circ} \mathrm{C}$. The moisture sorption isotherms of $\beta$-LG and gelatinized starch were sigmoid,

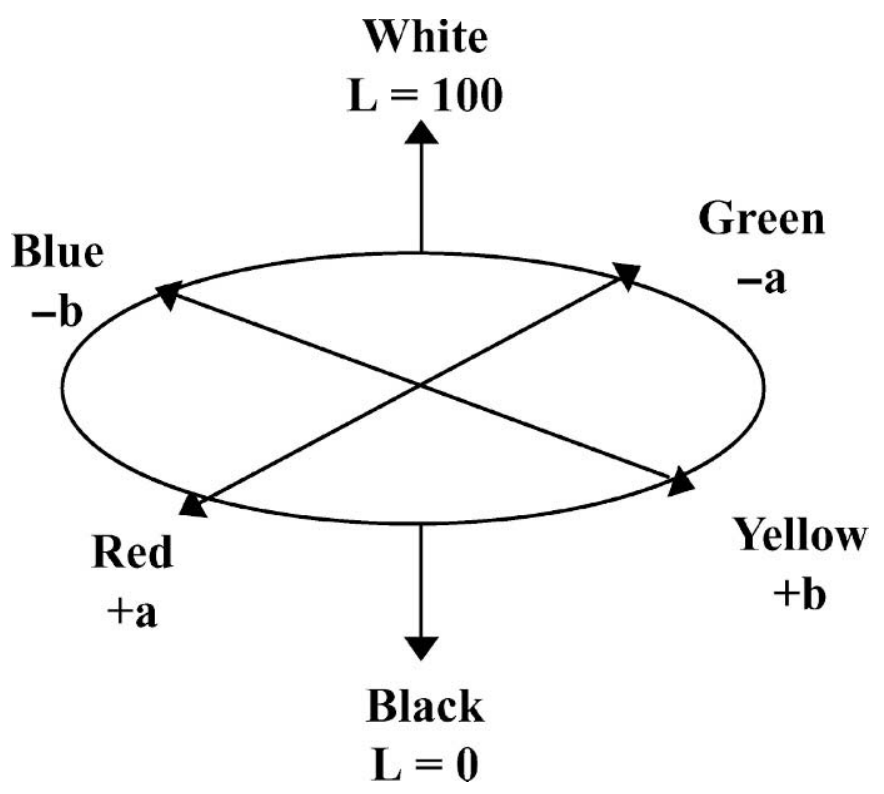

Figure 1. Chromatic space of CIE L* $a^{*} b^{*}$. and like most other hydrophilic proteins and polysaccharides, they absorbed a large quantity of water at a high RH (Mathlouti and Rogé, 2003). At RH above $75.4 \%, \beta$-LG absorbs more water than does gelatinized starch. However, amorphous lactose absorbs less water than either starch or $\beta$-LG because of the crystallization phenomenon that occurs above $43.2 \% \mathrm{RH}$, which has been observed (break point on the lactose curve) by numerous authors (Darcy and Buckton, 1997; Jouppila et al., 1997; Mazzobre et al., 2001; Thomas et al., 2004a). Amorphous lactose is hygroscopic, and water increases the molecular mobility and induces crystallization. During the crystallization process, lactose releases water, which can be observed as a break point on the moisture sorption curve. The moisture sorption isotherms of the 2 formulas (F80/ $10 / 10$ and F50/25/25) were placed between the lactose, starch, and $\beta$-LG curves. The sorption properties of the formulas depended on the sorption properties of the components.

\section{Lactose Crystallization}

In our experiments, the $\mathrm{RH}$ of lactose crystallization was delayed compared with pure lactose. Knudsen et al. (2002) explained that lactose crystallization is delayed because of a competitive absorption of water by the milk proteins. Moreover, Thomas et al. (2004a) showed that when the components are mixed independently after the drying process, the crystallization $\mathrm{RH}$ does not change.

Lactose crystallization occurred over time and was a time-dependent phenomenon. Indeed, for some formulas, lactose crystallization was noted at different $\mathrm{RH}$ over time. The differences in induction time indi- 


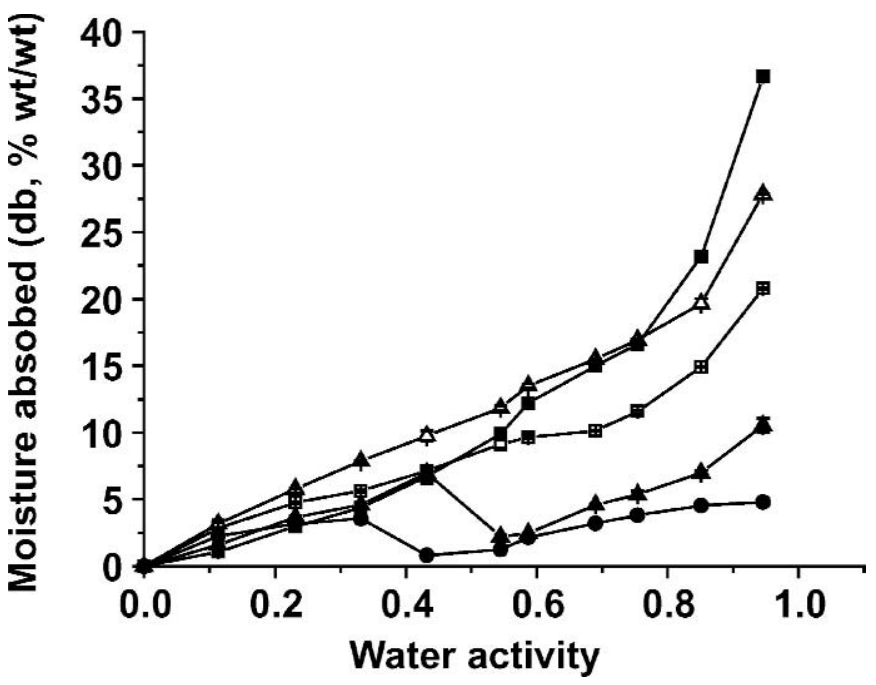

Figure 2. Moisture sorption isotherms of $\beta$-LG $(\boldsymbol{\square})$, starch $(\triangle)$, and lactose (-) and 2 infant formulations, F50/25/25 (lactose/starch/ $\beta$-LG, by wt). ( $\square$ ) and F80/10/10 ( $\boldsymbol{\Delta}$ ), after 3 mo of storage at $20^{\circ} \mathrm{C}$. $\mathrm{db}=$ Dry basis. Error bars indicate standard deviation; each value was calculated from 3 repetitions.

cate differences in the tendency for amorphous lactose to absorb water. For some formulas, water liberation (showing the crystallization phenomenon) occurred at higher $\mathrm{RH}$ than the lactose crystallization $\mathrm{RH}$, confirming that the effect of each component was not additive. Table 2 shows the crystallization $\mathrm{RH}$ for each formula. For some formulas, crystallization occurred at different $\mathrm{RH}$ over time. The first $\mathrm{RH}$ could be observed after $1 \mathrm{~d}$ and the second and third later on. The crystallization $\mathrm{RH}$ decreased with an increasing percentage of lactose. Jouppila and Roos (1994) studied the crystallization phenomenon in whole and skim milk, and they compared their results with pure lactose. They proposed that milk protein could retard this phenomenon. In addition, carboxymethyl cellulose and some proteins, such as recombinant human growth hormone (rhGH), could retard lactose crystallization (Karmas et al., 1992; Costantino et al., 1998). The crystallization of amorphous lactose has been related to its $T_{\mathrm{g}}$; this phenomenon occurs above the $T_{\mathrm{g}}$ (Jouppila and Roos, 1994). The $T_{\mathrm{g}}$ is increased by high molecular weight proteins and carbohydrates in the system (although not in all cases); thus, to exceed the $T_{\mathrm{g}}$ under the same conditions, it is necessary to increase the $\mathrm{RH}$. However, other authors have shown that retarding the crystallization in a system containing sugar that colyophilized with polymers and proteins, such as rhGH, does not depend on an increase in the system's $T_{\mathrm{g}}$ (Mazzobre et al., 2001). In addition, crystallization can be attributed to thermodynamic, geometric, or kinetics factors associated with modification of the mo-

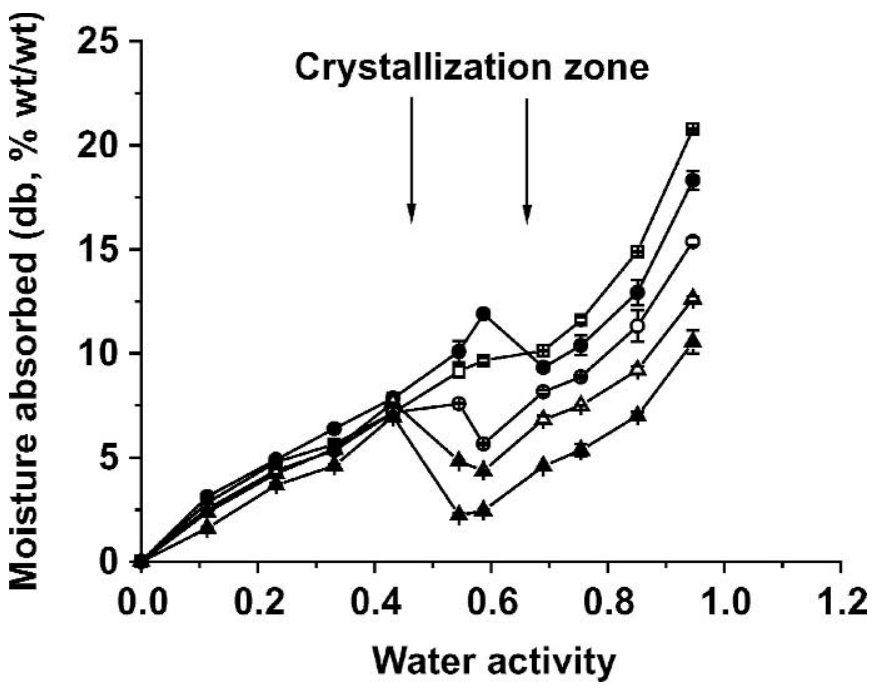

Figure 3. Moisture sorption isotherms of formulations (lactose/ starch/ $\beta$-LG, by wt) F50/25/25 ( $\square$ ), F57.5/21.25/21.25 (๑), F65/17.5/ $17.5(\bigcirc)$, F72.5/13/75/13.75 $(\triangle)$, and F80/10/10 ( $\Delta$ ) after 3 mo of storage at $20^{\circ} \mathrm{C} . \mathrm{db}=$ Dry basis. Error bars indicate standard deviation; each value was calculated from 3 repetitions.

lecular environment in the combined systems, which probably affects nucleation and crystal growth. Based on the hypothesis that sugars could replace water on a dried protein, it is possible that there was a solidstate interaction between the protein and sugar or between the sugar and sugar that was masking water monolayer sites from the humidified atmosphere. The interactions between these components had an important effect on crystallization $\mathrm{RH}$ and had no effect on the moisture sorption of samples.

Figure 3 shows the moisture sorption isotherms of different formulas at equilibrium. As the percentage of lactose increased, the moisture absorption and crystallization $\mathrm{RH}$ decreased. The amount of water absorbed by the formula increased with increasing amounts of $\beta$-LG and starch.

\section{Onset and Kinetics of Crystallization}

The development of crystallinity during storage was studied at $20^{\circ} \mathrm{C}$ and different $\mathrm{RH}$, as shown in Figure 4. This combination was chosen because our main interest was in the effects of $\mathrm{RH}$ on lactose crystallization in the formulas containing a high lactose content. Figure $4 \mathrm{a}$ shows the moisture sorption isotherms of $\mathrm{F} 50 /$ $25 / 25$ during storage at $20^{\circ} \mathrm{C}$. The crystallization $\mathrm{RH}$ of this formula was at $75.4 \% \mathrm{RH}$ and could be determined after $1 \mathrm{~d}$ of storage at this RH. It is clear from this figure that water liberation (lactose crystallization) occurred during storage at $75.4 \% \mathrm{RH}$ and that it took approximately 2 wk to reach equilibrium. The break 

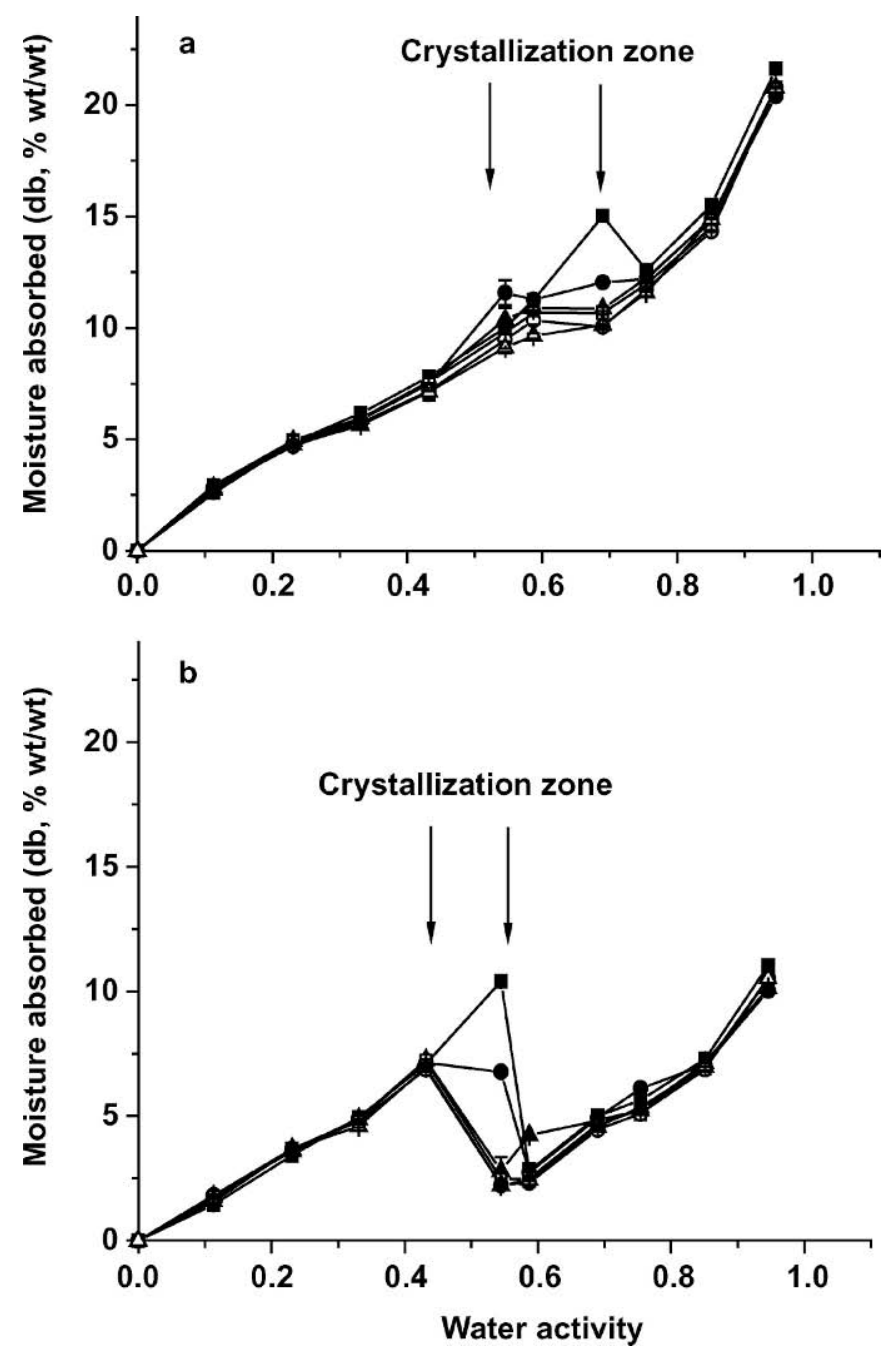

Figure 4. Moisture sorption isotherm changes during storage at $20^{\circ} \mathrm{C}$ : (a) F50/25/25; (b) F80/10/10 (lactose/starch/ $\beta$-LG, by wt). (口) 1

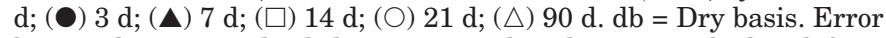
bars indicate standard deviation; each value was calculated from 3 repetitions.

point for F50/25/25 after equilibrium was not as clear as that for F80/10/10 because the water liberated was absorbed by $\beta$-LG and gelatinized starch. The moisture sorption isotherm curve was the same as a sigmoid isotherm curve. Figures $5 \mathrm{a}$ and $5 \mathrm{~b}$ show the moisture content changes of F50/25/25 and F80/10/10 at $4 \mathrm{RH}$ during storage. In this figure, the storage time is presented as the square root of time (day) to show the results more clearly and relate them to diffusion processing. For F50/25/25, water liberation occurred at $69 \%$, and at 59,54 , and $43 \% \mathrm{RH}$, lactose was in an amorphous state. In the case of F80/10/10, water liberation occurred at 54.5\%, and at 58.7 and $69 \%$, lactose was in a crystallized state. The moisture content of F80/10/10 at $43.2 \%$ was higher than that of samples
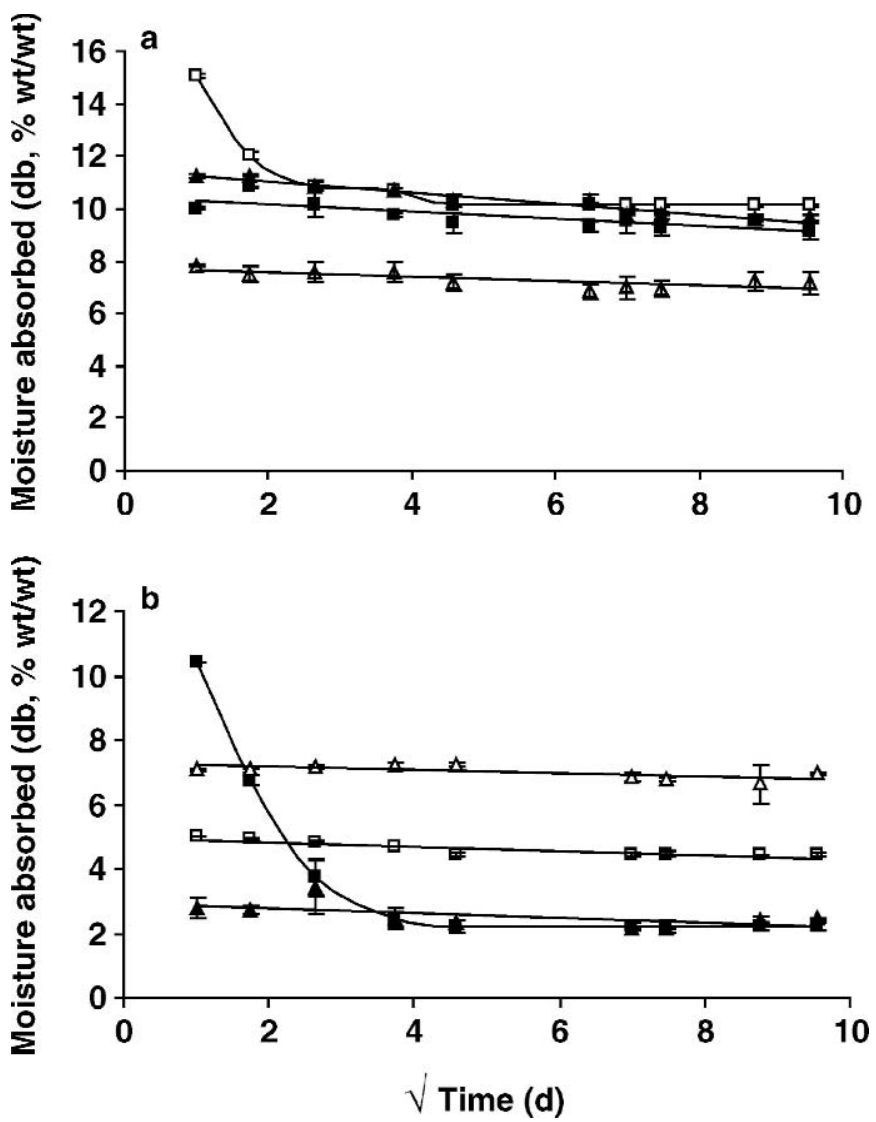

Figure 5. Moisture of (a) F50/25/25 (lactose/starch/ $\beta$-LG, by wt)

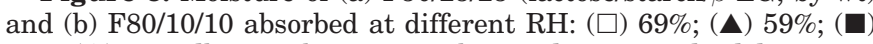
$54 \%$; $\triangle) 43 \%$. db = Dry basis. Error bars indicate standard deviation; each value was calculated from 3 repetitions.

stored at 54.5, 58.7, 69\%, because the lactose was amorphous at $43.2 \% \mathrm{RH}$. The crystallization delay was observed for different products containing a mixture of proteins or polysaccharides and lactose or other sugars, and it was attributed to a higher $T_{\mathrm{g}}$ or interactions among the components. Figure $4 \mathrm{~b}$ shows that for F80/ $10 / 10$, crystallization occurred at $\geq 54.5 \% \mathrm{RH}$. The equilibrium times for all the formulas at lower than $43.2 \% \mathrm{RH}$ was less than $1 \mathrm{wk}$ and were higher than $43.2 \% \mathrm{RH}$ until $12 \mathrm{wk}$ for different formulas. For example, the equilibrium time for F80/10/10 was $21 \mathrm{~d}$ at $54.5 \% \mathrm{RH}$, and for F72.5/13.75/13.75, the equilibrium time was $60 \mathrm{~d}$ at $54.5 \% \mathrm{RH}$. In the case of F72.5/13.75/ 13.75 , the first crystallization $\mathrm{RH}$ was at $69 \% \mathrm{RH}$ (and could be observed after $1 \mathrm{~d}$ ), the second was at $58.7 \%$ (after $3 \mathrm{~d}$ ), and the third was at $54.5 \%$ (after $56 \mathrm{~d}$ ) of conservation. As the percentages of starch and $\beta$-LG increased, the equilibrium time and crystallization $\mathrm{RH}$ increased. This may be because starch and $\beta$-LG changed the environment of lactose and prevented it from absorbing moisture. The molecular weight of $\beta$ - 
LG is 18,300 and that of starch is much higher than $\beta$-LG; thus, starch and $\beta$-LG limited the diffusion phenomenon and increased the viscosity of the system. Numerous authors (Mazzobre et al., 2001; Knudsen et al., 2002) have shown a delay of crystallization, but the reasons for this are not clear.

In this study we used gelatinized starch. During the gelatinization process, the hydrogen bonds between glucose chains in the crystallites were primarily disrupted, and perhaps some of those in the amorphous regions as well. Hydrogen bonds were formed when the gelatinized starch mixed with lactose and $\beta$-LG, and this might have retarded lactose crystallization.

Our results showed that adding $\beta$-LG and starch to formulas changed the kinetics of lactose crystallization. Many parameters affect lactose crystallization, such as changes to the molecular environment and interactions between lactose, $\beta$-LG, and starch in the solid state that replace protein or polysaccharides by water in the powdered state. As the quantity of $\beta$-LG and starch increased in the formulas, the crystallization $\mathrm{RH}$ or the delay time (the time required for lactose crystallization at the same $\mathrm{RH}$ ) increased. Many parameters played an important role in the delay time, such as the moisture sorption rate of lactose, viscosity changes caused by adding $\beta$-LG and starch, and prevention of moisture sorption by $\beta$-LG and starch. Moreover, the competition among the 3 components in moisture absorption was important. Under the same conditions, $\beta$-LG and starch absorbed more water than did lactose (Figure 2).

\section{Effect of Starch and $\beta$-LG on Moisture Sorption and Color Changes}

A mixture design was used to study the moisture sorption properties and color changes of samples during $3 \mathrm{mo}$ of storage at $20^{\circ} \mathrm{C}$ and at different $\mathrm{RH}$. A cubic model was proposed to explain the effect of each component and the $\mathrm{RH}$ on the moisture sorption of samples. Linear and cubic models were used to correlate the effects of formula compositions at $94.6 \% \mathrm{RH}$ for moisture sorption and at $75.4 \% \mathrm{RH}$ for the color changes of samples, respectively. A first series of models was proposed to clarify the effect of the components on moisture sorption and color $\left(\mathrm{L}^{*}\right.$ and $\left.\mathrm{b}^{*}\right)$ at a constant RH. In addition, a second series of models was suggested by adding the $\mathrm{RH}$ as a process condition to find a mathematical model to predict the moisture sorption and color changes of formulas at different $\mathrm{RH}$. A quadratic model was found to elucidate the effect of $\mathrm{RH}$ on the moisture sorption and color changes of samples.
Table 3. Estimations of coefficients and probabilities of the models (Eq. 1)

\begin{tabular}{llrl}
\hline Response & Name & Coefficient & Probability $>F$ \\
\hline Moisture sorption & Model & & $<0.0001$, significant \\
& $k_{1}$ & 3.770 & $<0.0001$ \\
& $k_{2}$ & 31.767 & $<0.0001$ \\
& $k_{3}$ & 43.563 & $<0.0001$ \\
Color b* & Model & & $<0.0001$, significant \\
& $k_{1}$ & 0.758 & $<0.0001$ \\
& $k_{2}$ & 33.739 & $<0.0001$ \\
& $k_{3}$ & -39.455 & $<0.0001$ \\
& $k_{1,2}$ & -9.430 & 0.0316 \\
& $k_{1,3}$ & 155.014 & 0.0913 \\
& $k_{2,3}$ & 249.089 & 0.0220 \\
Color L* & $k_{1,2,3}$ & -861.619 & 0.0302 \\
& Model & & 0.0252, significant \\
& $k_{1}$ & 47.954 & 1 \\
& $k_{2}$ & -525.859 & 1 \\
$k_{3}$ & -425.148 & 1 \\
& $k_{1,2}$ & $1,027.679$ & 0.0173 \\
& $k_{1,3}$ & 840.124 & 0.0830 \\
& $k_{2,3}$ & $3,705.238$ & 0.0056 \\
\hline
\end{tabular}

${ }^{1} P$-values less than 0.0500 indicate the model terms are significant; $P$-values greater than 0.1000 indicate the model terms are not significant.

The coefficients of the cubic model were estimated by the least squares method from the results given by the experiment. Table 3 shows these coefficients for each factor according to the following equation for maximum moisture sorption at $94.6 \% \mathrm{RH}$, and for colors $\mathrm{L}^{*}$ and $\mathrm{b}^{*}$ at $75.4 \% \mathrm{RH}$ after $3 \mathrm{mo}$ of storage at $20^{\circ} \mathrm{C}$ :

$$
\begin{array}{r}
Y=k_{1} X_{1}+k_{2} X_{2}+k_{3} X_{3}+k_{1,2} X_{1} X_{2} \\
+k_{1,3} X_{1} X_{3}+k_{2,3} X_{2} X_{3}+k_{1,2,3} X_{1} X_{2} X_{3}
\end{array}
$$

where $X_{1}, X_{2}$, and $X_{3}$ are the quantities of lactose, starch, and $\beta$-LG, respectively, and $k_{1}, k_{2}$, and $k_{3}$ are the coefficients. Response $Y$ is the maximum moisture sorption at $94.6 \% \mathrm{RH}$, color $\mathrm{L}^{*}$, and color $\mathrm{b}^{*}$.

A linear model was found to explain the effect of each component on moisture sorption at all $\mathrm{RH}$ above the lactose crystallization $\mathrm{RH}$. Thus, by eliminating the interactions from the previous equation, we have the effect of each component on moisture sorption:

$$
Y(94.6 \%)=3.77 X_{1}+31.77 X_{2}+43.56 X_{3}
$$

where $Y(94.6 \%)$ is the moisture sorption of samples at $94.6 \% \mathrm{RH}$. This equation shows that the moisture sorption properties of the formulas depended on the moisture sorption behaviors of each component and that the interactions had no significant effect. Thomas et al. (2004a) showed the same results for lactose and $\beta$-LG.

Equations 3, 4, and 5 show the moisture sorption properties of the formulas at $\mathrm{RH}$ of 85.1, 75.4, and 69\%: 


$$
\begin{aligned}
& Y(85 \%)=1.72 X_{1}+26.46 X_{2}+30.28 X_{3} \\
& X(75 \%)=1.37 X_{1}+22.27 X_{2}+23.09 X_{3} \\
& X(69 \%)=1.43 X_{1}+20.39 X_{2}+19.06 X_{3} .
\end{aligned}
$$

Equations 2 to 5 agree with the data shown in Figure 1. $\beta$-Lactoglobulin and gelatinized starch had a greater effect on moisture sorption properties at $\mathrm{RH}$ above $69 \%$ and below $69 \%$, respectively.

A quadratic model (Eq. 6) was used to predict the effect of $\mathrm{RH}$ and the composition of each formula on moisture sorption properties. In this model, the effect of each component was linear, as shown in Equations 2 to 5 , and the $\mathrm{RH}$ had a quadratic effect on moisture sorption properties:

$$
\begin{gathered}
Y=37.901 X_{1}+35.133 X_{2}+101.577 X_{3}-97.374 X_{1} X_{4} \\
-69.275 X_{2} X_{4}-273.949 X_{3} X_{4}+64.643 X_{1} X_{4}{ }^{2} \\
+69.249 X_{2} X_{4}{ }^{2}+223.995 X_{3} X_{4}{ }^{2} .
\end{gathered}
$$

The statistical analyses (all interactions between the components and $\mathrm{RH}$ ) were significant, and $\mathrm{R}^{2}$ results $\left(\mathrm{R}^{2}=0.98\right)$ showed strong agreement between the calculated and experimental values.

The degree of Maillard reaction is measured by different methods, such as the content of hydroxymethyl furfural or other Maillard products such as furosine (Van Renterghem and De Block, 1996), color and pigment formation (Morales and Van Boekel, 1998; Burin et al., 2000), and free monosaccharides (Villamiel and Corzo, 2000). The effect of nonenzymatic browning on the nutritional and physicochemical properties of infant formula and dried milk has been reviewed by numerous researchers (Thomas et al., 2004b; Nasirpour et al., accepted). Nonenzymatic browning was studied by measuring the sample colors at $4 \mathrm{RH}$ (11.3, $43.2,54.5$, and $75.4 \%$ ) and after 3 mo of storage. A cubic model (Eq. 1) was used to estimate the color changes after 3 mo of storage at different $\mathrm{RH}$. The coefficients and probabilities of this model are presented in Table 4. This model was valuable for $\mathrm{RH}$ of 75.4 and $54.5 \%$ (i.e., the crystallization occurred in samples). A linear model was found for samples stored at $43.2 \% \mathrm{RH}$. In this case, the interaction effect was not significant. As mentioned, all formulations were not crystallized at $43.2 \% \mathrm{RH}$. As numerous authors have shown (Labuza et al., 1970; Buera et al., 1987; Roos and Himberg, 1994), the rate of nonenzymatic browning is affected by the water content and storage

\begin{tabular}{|c|c|c|c|}
\hline Response & Name & Coefficient & Probability $^{2}$ \\
\hline Color b* $(54.5 \% \mathrm{RH})$ & $\begin{array}{l}\text { Model } \\
k_{1} \\
k_{2} \\
k_{3} \\
k_{1,2} \\
k_{1,3} \\
k_{2,3} \\
k_{1,2,3}\end{array}$ & $\begin{array}{r}24.06 \\
141.49 \\
143.88 \\
-281.08 \\
-266.85 \\
-863.38 \\
1,358.26\end{array}$ & $\begin{array}{r}<0.0001 \\
<0.0001 \\
<0.0001 \\
0.0011 \\
0.0018 \\
0.0049 \\
0.0008\end{array}$ \\
\hline Color L* $(54.5 \% \mathrm{RH})$ & $\begin{array}{l}\text { Model } \\
k_{1} \\
k_{2} \\
k_{3} \\
k_{1,2} \\
k_{1,3} \\
k_{2,3} \\
k_{1,2,3}\end{array}$ & $\begin{array}{c}113.65 \\
317.72 \\
369.38 \\
-406.15 \\
-495.04 \\
-156.849 \\
2,455.47\end{array}$ & $\begin{array}{l}0.0003 \\
0.0003 \\
0.0003 \\
0.0621 \\
0.012 \\
0.0308 \\
0.0077\end{array}$ \\
\hline Color b* $(43.2 \% \mathrm{RH})$ & $\begin{array}{l}\text { Model } \\
k_{1} \\
k_{2} \\
k_{3} \\
k_{1,2} \\
k_{1,3} \\
k_{2,3} \\
k_{1,2,3}\end{array}$ & $\begin{array}{l}3.62 \\
-2.47 \\
4.52 \\
0 \\
0 \\
0 \\
0\end{array}$ & $\begin{array}{l}0.003 \\
0.003 \\
0.003 \\
\text { NS } \\
\text { NS } \\
\text { NS } \\
\text { NS }\end{array}$ \\
\hline Color L* $(43.2 \% \mathrm{RH})$ & $\begin{array}{l}\text { Model } \\
k_{1} \\
k_{2} \\
k_{3} \\
k_{1,2} \\
k_{1,3} \\
k_{2,3} \\
k_{1,2,3}\end{array}$ & $\begin{array}{c}92.99 \\
99.2 \\
100.76 \\
0 \\
0 \\
0 \\
0 \\
\end{array}$ & $\begin{array}{l}0.0026 \\
0.0026 \\
0.0026 \\
\text { NS } \\
\text { NS } \\
\text { NS } \\
\text { NS }\end{array}$ \\
\hline
\end{tabular}
temperature, the system composition, and $\mathrm{pH}$. Labuza et al. (1970) showed that dehydrated foods had a slow browning rate at a low water activity; the maximum
Table 4. Estimation of coefficients and probabilities for color changes after storage $^{1}$

${ }^{1} \mathrm{RH}=$ relative humidity; $\mathrm{NS}=$ not significant.

${ }^{2} P$-values less than 0.0500 indicate the model terms are significant; $P$-values greater than 0.1000 indicate the model terms are not significant.

browning rate occurred at a medium $\mathrm{RH}$ (around 70) for intermediate-moisture foods. The rate of nonenzymatic browning is extremely low below the $T_{\mathrm{g}}$, maybe because diffusion is limited (Roos and Himberg, 1994); at temperatures greater than the $T_{\mathrm{g}}$, this rate is higher (Karmas et al., 1992). The diffusion coefficient is inversely proportional to the viscosity of the system. If the viscosity of the system decreases above the $T_{\mathrm{g}}$, then the rate of nonenzymatic browning depends on $\left(T-T_{\mathrm{g}}\right)$.

The color $b^{*}$ shows changes in the yellow color. In this model, for samples stored at 75.4 and $54.5 \% \mathrm{RH}$, the effects of lactose, starch, and $\beta$-LG and the interactions among the 3 components were positive, and the interactions between lactose and starch, lactose and $\beta$ LG, and starch and $\beta$-LG were negative. Nevertheless, starch had no positive effect on nonenzymatic browning (as it is not a reducing sugar). Moreover, as Tables 3 and 4 show, it had nearly the same effect as $\beta$-LG on color changes. By eliminating the interactions from 
these models (models not presented), starch had a negative effect on color $b^{*}$ (i.e., it protected the samples against color changes) at $75.4,54.5$, and $43.2 \% \mathrm{RH}$, as predicted.

A linear $\times$ cubic model (crossed model) was used to predict the sample color $b^{*}$ during storage, with $\mathrm{RH}$ and time considered as 2 numerical process parameters. Equation 7 presents this model:

$$
\begin{gathered}
Y(b)=2.126 X_{1}-3.33 X_{2}+10.456 X_{3}-5.074 X_{1} X_{4} \\
+0.043 X_{1} X_{5}+29.657 X_{2} X_{4}-0.082 X_{2} X_{5}-48.552 X_{3} X_{4} \\
-0.03 X_{3} X_{5}+10.434 X_{1} X_{4}^{2}-5.3 E-4 X_{1} X_{5}^{2} \\
-39.94 X_{2} X_{4}^{2}+1.036 E-3 X_{2} X_{5}^{2}+61.275 X_{3} X_{4}^{2} \\
-9.731 E-5 X_{3} X_{5}^{2}+0.084 X_{1} X_{4} X_{5} \\
-0.169 X_{2} X_{4} X_{5}+0.183 X_{3} X_{4} X_{5}
\end{gathered}
$$

where $Y(b)$ is color $b^{*}$ at a defined $\mathrm{RH}$ and time, and $X_{1}, X_{2}, X_{3}, X_{4}$, and $X_{5}$ are, respectively, the percentages of lactose, starch, and $\beta$-LG; time (days); and RH. From this model, color $b^{*}$ could be calculated over time (from 7 to $92 \mathrm{~d}$ ) and at different $\mathrm{RH}$ (11.3 to $75.4 \%)$. The probability and $\mathrm{R}^{2}$ results $\left(\mathrm{R}^{2}=0.93\right)$ provided proof of good agreement between the calculated and experimental values. Figures $6 \mathrm{a}$ and $6 \mathrm{~b}$ show the positions of the points chosen for the models and for validation of the models, respectively.

Nonenzymatic browning occurs in samples containing proteins and reducing sugars. This reaction is important in different ways, such as on the nutritional quality of proteins, changes in the organoleptic quality of samples, and the production allergenic compounds. This model (Eq. 7) could predict the yellow color changes in formulas containing lactose, $\beta$-LG (protein), and starch during storage. Color changes could be controlled by changing the storage parameters (Ottenhof et al., 2003) and formula components (lactose, $\beta$-LG, and starch), and consequently control nonenzymatic browning. In this model of $\mathrm{RH}$, time had a positive effect on yellow color development and starch had a negative effect.

\section{CONCLUSIONS}

The lactose crystallization $\mathrm{RH}$ is changed by adding proteins or saccharides. This phenomenon was observed previously, and some researchers believe that changes in the $T_{\mathrm{g}}$ in lactose mixtures are responsible. However, in some systems, such as those with rhGH and trehalose, the lactose crystallization $\mathrm{RH}$ is changed without changing the system $T_{\mathrm{g}}$. In this condition, other parameters such as molecular environment
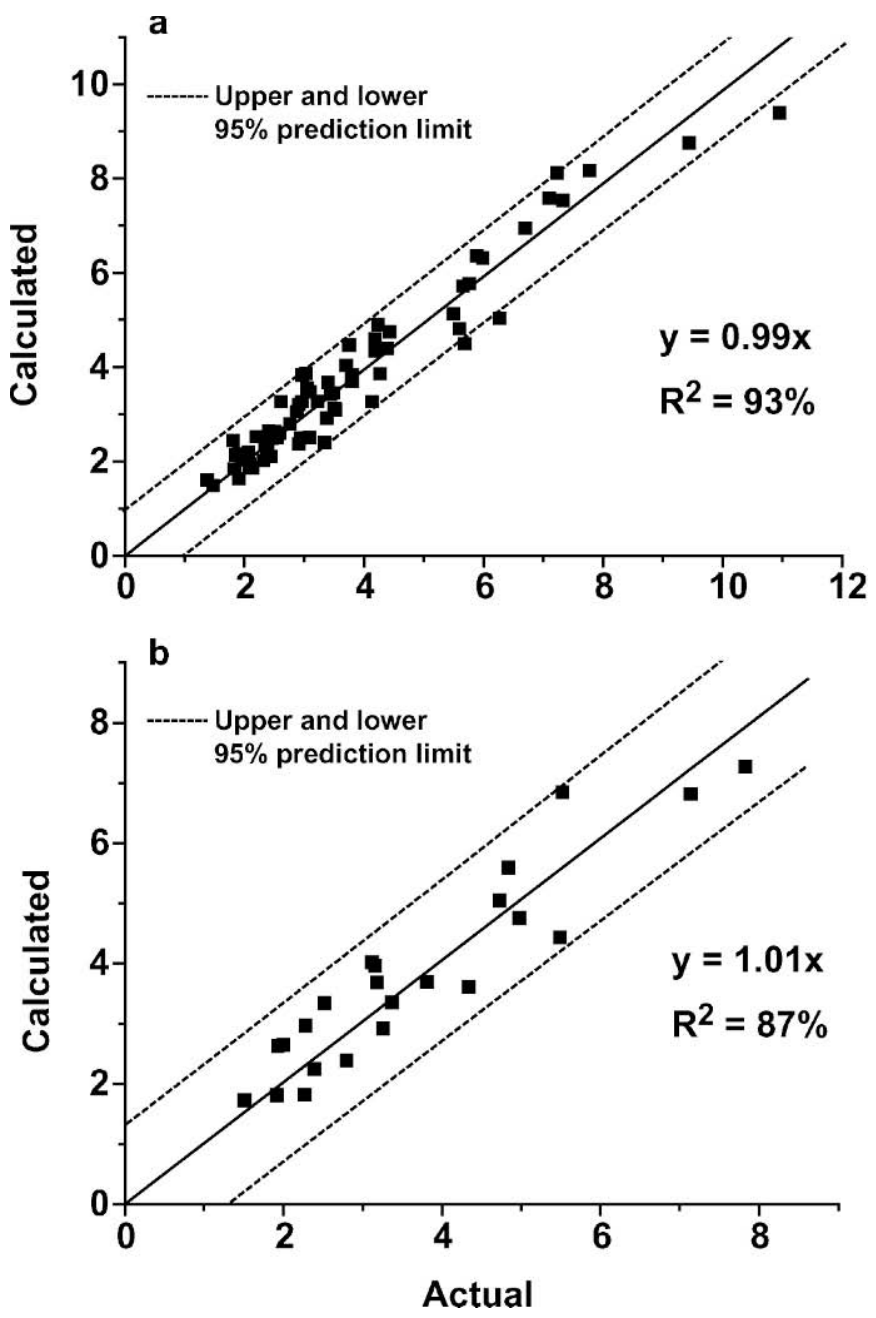

Figure 6. Correlation between actual and calculated data. Data were used (a) for the model and (b) for validation of the model.

changes and interactions among the components affect lactose crystallization.

The stabilization of lactose against crystallization could also be attributed to preferential exclusion, surface activity, the steric hindrance of lactose-protein and lactose-polysaccharide, or the increased of viscosity of systems that limits structural movement. During lyophilization, water is replaced by lactose and starch in the $\beta$-LG structure, and the long chain length may interfere with intermolecular hydrogen bonding between lactose and $\beta$-LG. Therefore, these bonds prevent or retard lactose crystallization.

The nonenzymatic reaction occurs progressively over time and is temperature dependent. Reducing sugars such as glucose, maltose, lactose, and some forms of starch hydrolysates may react with the amino group of lysine in formulas containing intact proteins or with any amino acids or small peptides. The reaction 
may adversely affect protein quality by decreasing the bioavailability of some amino acids (Hurrell and Carpenter, 1981). By modifying the process and storage parameters, the quality of baby foods could be improved. The mathematical model we proposed could be used to predict the sample color during storage at different RH. This model suggests that by increasing the quantity of gelatinized starch in the formula, the color $b^{*}$ changes would decrease. In the last step of lyophilization, water is replaced by lactose or starch. Starch is not a reducing sugar, and by replacing this carbohydrate in the protein structure, the active sites would decrease.

\section{ACKNOWLEDGMENTS}

This work was supported by the Ministry of Science, Research and Technology and by Isfahan University of Technology of Iran, both of which are gratefully acknowledged.

\section{REFERENCES}

Buckton, G., and P. Darcy. 1999. Assessment of disorder in crystalline powders-A review of analytical techniques and their application. Int. J. Pharm. 179:141-158.

Buera, M. P., J. Chirife, S. K. Resnik, and G. Wetzler. 1987. Nonenzymatic browning in liquid model systems of high water activity: Kinetics of color changes due to Maillard's reaction between different single sugars and glycine and comparison with caramelization browning. J. Food Sci. 52:1063-1067.

Burin, L., K. Jouppila, Y. Roos, J. Kansikas, and M. P. Buera. 2000. Color formation in dehydrated modified whey powder systems as affected by compression and $T_{\mathrm{g}}$. J. Agric. Food Chem. 48:5263-5268.

Cafaggi, S., R. Leardi, B. Parodi, G. Caviglioli, and G. Bignardi. 2003. An example of application of a mixture design with constraints to a pharmaceutical formulation. Chemom. Intell. Lab. Sys. 65:139-147.

Costantino, H. R., J. G. Curley, S. Wu, and C. C. Hsu. 1998. Water sorption behavior of lyophilized protein-sugar systems and implications for solid-state interactions. Int. J. Pharm. 166:211221.

Darcy, P., and G. Buckton. 1997. The influence of heating/drying on the crystallisation of amorphous lactose after structural collapse. Int. J. Pharm. 158:157-164.

Food Safety Authority of Ireland (FSAI). 2001. Guidance Note on the Implementation of European Communities (Infant Formulae and Follow-On Formulae) Regulations, 1998 to 2000. FSAI, Dublin, Ireland.

Greenspan, S. 1977. Humidity fixed points of binary saturated aqueous solutions. J. Res. Natl. Bur. Stand. 81:89-93.

Herrington, T. M., and A. C. Brandfield. 1984. Physico-chemical studies on sugar glasses. I. Rates of crystallization. J. Food Technol. 19:409-425.
Hurrell, R. F., and K. J. Carpenter. 1981. The estimation of available lysine in foodstuffs after Maillard reaction. Prog. Food Nutr. Sci. 5:159-176.

Jost, R., J.-C. Maire, F. Maynard, and M.-C. Secretin. 1999. Aspects of whey protein usage in infant nutrition, a brief review. Int. J. Food Sci. Technol. 34:533-542.

Jouppila, K., J. Kansikas, and Y. H. Roos. 1997. Glass transition, water placticization, and lactose crystallization in skim milk powder. J. Dairy Sci. 80:3152-3160.

Jouppila, K., and Y. H. Roos. 1994. Glass transition and crystallization in milk powders. J. Dairy Sci. 77:2907-2915.

Karmas, R., M. P. Buera, and M. Karel. 1992. Effect of glass transition temperature on rates of nonenzymatic browning in food systems. J. Agric. Food Chem. 40:873-879.

Kim, M. N., M. Saltmarch, and T. P. Labuza. 1981. Non-enzymatic browning of hygroscopic whey powders in open versus sealed pouches. J. Food Process. Preserv. 5:49-57.

Knudsen, J. C., H. S. Antanuse, J. Risbo, and L. H. Skibsted. 2002. Induction time and kinetics of crystallization of amorphous lactose, infant formula and whole milk powder as studied by isothermal differential scanning calorimetry. Milchwissenschaft 57:543-554.

Labuza, T. P., S. R. Tannenbaum, and M. Karel. 1970. Water content and stability of low-moisture and intermediate-moisture foods. Food Technol. 24:35-42.

Levine, H., and L. Slade. 1986. A polymer physicochemical approach to the study of commercial starch hydrolysis products (SHPs). Carbohydr. Polym. 6:213-244.

Mathlouti, M., and B. Rogé. 2003. Water vapour sorption isotherms and the caking of food powders. Food Chem. 82:61-71.

Mazzobre, M. F., G. Soto, J. M. Aguilera, and M. P. Buera. 2001. Crystallization kinetics of lactose in systems co-lyofilized with trehalose. Analysis by differential scanning calorimetry. Food Res. Int. 34:903-911.

Morales, F. J., and M. A. J. S. Van Boekel. 1998. A study on advanced Maillard reaction in heated casein/sugar solutions: Colour formation. Int. Dairy J. 8:907-915.

Nasirpour, A., J. Scher, and S. Desobry. Baby foods: Formulations and interactions. Crit. Rev. Food Sci. Nutr., accepted.

Ottenhof, M. A., W. MacNaughtan, and I. A. Farhat. 2003. FTIR study of state and phase transition of low moisture sucrose and lactose. Carbohydr. Res. 338:2195-2202.

Roos, Y. H. 1995. Characterization of food polymers using state diagrams. J. Food Eng. 24:339-360.

Roos, Y. H., and M. J. Himberg. 1994. Nonenzymatic browning behavior, as related to glass transition of a food model at chilling temperature. J. Agric. Food Chem. 42:893-898.

Roos, Y. H., and M. Karel. 1992. Crystallization of amorphous lactose. J. Food Sci. 57:775-777.

Slade, L., and H. Levine. 1991. Beyond water activity: Recent advances based on an alternative approach to the assessment of food quality and safety. Crit. Rev. Food Sci. Nutr. 30:115-360.

Thomas, M. E. C., J. Scher, and S. Desobry. 2004a. Lactose/ $\beta$-lactoglobulin interaction during storage of model whey powders. J. Dairy Sci. 87:1158-1166.

Thomas, M. E. C., J. Scher, and S. Desobry. 2004b. Milk powder ageing: Effect on physical and functional properties. Crit. Rev. Food Sci. Nutr. 44:297-322.

Van Renterghem, R., and J. De Block. 1996. Furosine in consumption milk and milk powders. Int. Dairy J. 6:371-382.

Villamiel, M., and N. Corzo. 2000. Changes in furosine, free monosaccharides and $\beta$-lactoglobulin during storage of dried milk products. Milchwissenschaft 55:90-92.

Vuataz, G. 2002. The phase diagram of milk: A new tool for optimising the drying process. Lait 82:485-500. 